\title{
Differences in Neuronal Numbers, Morphology and Developmental Apoptosis in Mice Nigra Provide Evidence of Ontogenic Origin of Vulnerability to Parkinson's Disease
}

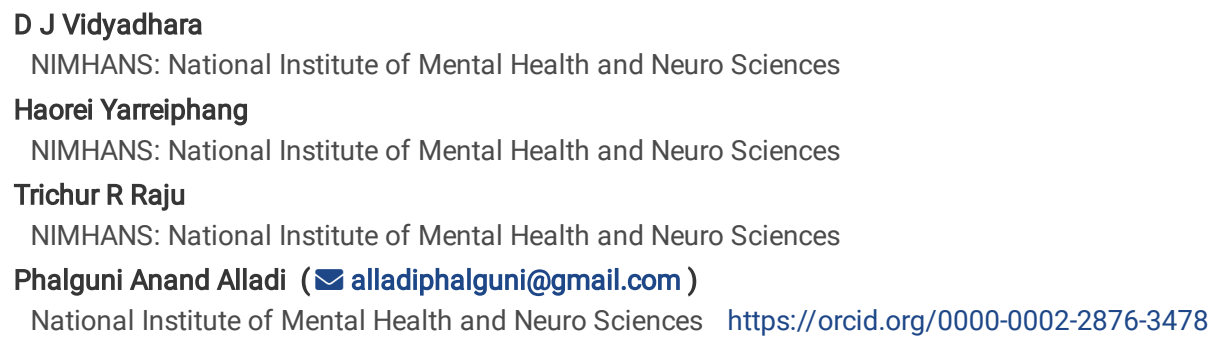

\section{Research Article}

Keywords: Parkinson's disease, Dopaminergic (DA) neurons, Substantia nigra pars compacta, Postnatal Development, MPTP susceptibility, Developmental cell death

Posted Date: April 30th, 2021

DOI: https://doi.org/10.21203/rs.3.rs-452355/v1

License: @ (i) This work is licensed under a Creative Commons Attribution 4.0 International License. Read Full License 


\section{Abstract}

Parkinson's disease (PD) prevalence varies by ethnicity. In an earlier study we replicated the reduced vulnerability to PD in an admixed population, using 1methyl-4-phenyl-1,2,3,6-tetrahydropyridine (MPTP)-susceptible C57BL/6J, MPTP-resistant CD-1 and their F1 crossbreds. In the present study we investigated if the differences have a developmental origin. Substantia nigra was evaluated atpostnatal days 2 (P2), P6, P10, P14, P18, and P22. C57BL/6J mice had smaller nigra and fewer dopaminergic neurons than the CD-1 and crossbreds at P2, which persisted through development. A significant increase in numbers and nigral volume was observed across strains till P14. A drastic decline thereafter was specific to C57BL/6J. CD-1 and crossbreds retained their numbers from P14 to stabilize with supernumerary neurons at adulthood. The neuronal size increased gradually to attain adult morphology at P10 in the resistant strains, vis-à-vis at P22 in C57BL/6J. Accordingly, in comparison to C57BL/6J, the nigra of CD-1 and reciprocal crossbreds possessed cyto-morphological features of resilience, since birth. The considerably lesser dopaminergic neuronal loss in the CD-1 and crossbreds seen at P2, P14 and thereafter was complemented by attenuated developmental cell death. The differences in programmed cell death were confirmed by reduced TUNEL labelling, AIF and caspase-3 expression. GDNF expression aligned with the cell death pattern at P2 and P14 in both nigra and striatum. Earlier maturity of nigra and its neurons appear to be better features that reflect as MPTP-resistance at adulthood. Thus variable MPTP-vulnerability in mice and also differential susceptibility to PD in humans may arise early during nigral development.

\section{Introduction:}

Degeneration of A9 subset of dopaminergic (DA) neurons of the substantia nigra pars compacta (SNpc) is a key neuropathological hallmark of Parkinson's disease (PD). A loss of $50-60 \%$ DA neurons is a pre-requisite to manifest the motor abnormalities [1-4] which points at the requirement of a critical numbers of DA neurons for normal function or setting off the pathology. In this context, Fahn[5] hypothesised that individuals born with lesser number of nigral neurons are more likely to develop PD, which raises a possibility that quantitative differences between nigral neuronal numbers could be the basis for ethno-racial bias in PD prevalence. USA-based Caucasians have high prevalence of PD $(329.3 / 100,000)$ [6] along with the European-Caucasians (108-257/100,000) [7]. A recent study on North American population revealed an alarming rise in PD prevalence to 572/100,000 [8]. A Chicago-based study documented age-related loss of nigral DA phenotype [9], while other Europe-based studies showed frank age-related neuronal loss [2, 10]. In contrast, Asian-Indians with lower PD prevalence $(52.7 / 100,000)$ [11] had relatively higher number of SNpc DA neurons with no age-related neuronal loss [12]. This along with subtle glial; dendritic and synaptic changes noted in this population $[13,14]$ might explain the lower prevalence of PD in them. Thus, DA neuronal numbers and their response to aging may play a vital role in shaping the individual's vulnerability to develop PD.

The prevalence of PD in admixed populations is of potential interest due to the complex genetic patterns resulting from admixing and the likelihood of alterations in the disease patterns. The Anglo-Indians who are the first-generation admixed population born to an Asian-Indian female and a Caucasian male are, surprisingly, at a much lesser risk for PD [15]. In the absence of autopsied tissues of this population, we designed an animal model of admixing by studying the F1 generation of 1-methyl-4-phenyl-1,2,3,6-tetrahydropyridine (MPTP)-resistant CD-1 mated with MPTP-susceptible C57BL/6J strains of mice. Our model effectively recapitulated the "much lesser risk for PD" seen in the Anglo-Indians citing the differences in cyto-morphological patterns, explaining the differential prevalence of PD to a considerable extent [16]. In brief, the C57BL/6J mice, which possessed fewer DA neurons, were highly vulnerable to MPTP, compared to CD-1, which had more of these neurons. Other DA phenotypes such as cellular size along with tyrosine hydroxylase (TH), Nurr1, PitX3, calbindin D28k, glial derived neurotrophic factor, caspase-3, mitochondrial fission/fusion proteins and interneuron related proteins also appeared to influence the MPTPinduced susceptibility/resistance [17-20, 16]. The F1 crossbreds of these strains were much better protected against MPTP, with the particularly striking finding of supernumerary nigral DA neurons and absence of neuronal loss in response to MPTP-toxicity. Preserved motor behavior and compensated/unaffected striatal local field potentials in PD reminiscent conditions in CD-1 and the crossbreds complement the cytomolecular observations [18]. These features indicate that admixing imparts resilience.

Cytomorphological and molecular features of maturation of the nigral DA neurons are seeded during ontogenesis [21, 22]. The total number of DA neurons at adulthood may thus be finalised during the postnatal period. Aspects like establishment of DA phenotype, synaptogenesis, trophic factor supply, levels of proapoptotic and anti-apoptotic proteins and other cytomolecular attributes during this period are critical determinants of their survival [23]. Study of substantia nigra DA neurons in different ethnicities during the formative period might reveal the mechanisms, however, due to the valid ethical constraints that limit the availability of human foetal and neonatal brain specimens, it is difficult to conduct such experiments.

In the fetal primate brains, apoptosis of DA neurons was observed midway through gestation i.e. embryonic day 80 and identified histologically by chromatin clumping in tyrosine hydroxylase-positive cells and confirmed by Terminal deoxynucleotidyltransferase (TdT) dUTP Nick-End Labeling (TUNEL) and caspase-3 staining[24], with a loss of at least $50 \%$ of the DA neurons. In developing rats, programmed cell death (PCD) in the midbrain DA system began at the end of gestation to peak in the postnatal period[25]. Caspase-3 and apoptosis inducing factor (AIF) are accepted modulators of apoptotic cascades in the developing nigra[26]. GDNF appears to be the most potent supporter of embryonic nigral DA neurons. Disruption of nuclear membrane integrity and release of proaggregant nuclear factors, such as histones, that may trigger a-synuclein aggregation which leads to cell death [27]. Developmental PCD is an important determinant of the size and function of a neuronal population at adulthood and its timing and magnitude is critical to understand the intrinsic and extrinsic factors that affect PCD in DA neurons.

In the present study, we evaluated the postnatal development of SNpc in our model of differential susceptibility using four mice strains i.e. C57BL/6J, CD-1 and their reciprocal crossbred strains, F1X1 and F1X2 [18, 16]. We performed stereological quantification to estimate the number of nigral neurons followed by the evaluation of morphological alterations and compared them with the features seen in adults. These estimations were conducted over the period of postnatal development i.e. P2 (postnatal day 2) to P22 on every 4th day, in order to earmark the critical developmental time points of 1) maximal cell loss 2) morphological maturation and 3) alterations in expression profile of tyrosine hydroxylase (TH). Apoptosis was evaluated by TUNEL assay. AIF and caspase-3 were evaluated by immunofluorescence and confocal microscopy-based evaluation at periods of peak apoptosis i.e. P2, P14 and P22 in SNpc. GDNF

Page 2/15 
expression was evaluated at P2 and P14 in the nigro-striatum. Our study provides experimental evidence that developmental apoptosis sculpts the nigra in terms of neuronal numbers and facilitates the identification of strain-specific critical window of maximum susceptibility of DA neurons.

\section{Materials And Methods:}

\subsection{Mice strains:}

The pregnant mice were housed in polypropylene cages under standard laboratory conditions with ad-libitum access to food and water. Age and gender matched neonates ( $n=6$ /group/experiment) born following mating of C57BL/6J female and CD-1 males were named F1X1, while the reciprocal ones were named F1X2 [16]. The experiments were performed in the light period (08:00-18:00h) in accordance with the guidelines of the Committee for the Purpose of Control and Supervision of Experiments on Animals (CPCSEA), New Delhi, India, that are based on NIH, USA guidelines.

\subsection{Tissue processing for immunohistochemistry and TUNEL:}

We anaesthetized neonates aged postnatal day 2 (P2), P6, P10, P14, P18 and P22 of each strain ( $\mathrm{n}=6 /$ strain/time-point) by halothane inhalation and perfused intracardially with saline followed by $4 \%$ buffered paraformaldehyde $(0.1 \mathrm{M}$ phosphate buffer; $\mathrm{pH} 7.4)$. The brains were quickly harvested and postfixed for $24-48 \mathrm{~h}$ at $4^{\circ} \mathrm{C}$. Cryoprotected midbrains (10\%, 20\%, and $30 \%$ sucrose in $0.1 \mathrm{M} \mathrm{PB}$ ) were cryosectioned (Leica Microsystems, Germany) at $40 \mu \mathrm{m}$. Serial sections were collected on gelatinized slides. Every third midbrain section from P2, P6, and P10 specimens and every sixth midbrain section from P14, P18, and P22 were immunostained, a slight modification of earlier reports [23].

\subsection{Immuno-peroxidase staining of tyrosine hydroxylase $(\mathrm{TH})$ :}

Briefly, following the quenching of endogenous peroxidase by $0.1 \% \mathrm{H}_{2} \mathrm{O}_{2}$ in $70 \%$ methanol, the non-specific staining was blocked with $3 \%$ buffered bovine serum albumin (BSA). The sections were sequentially incubated with the rabbit polyclonal anti-TH antibody (1:500, SC-25269, Santacruz Biotechnology Inc, USA;72hr), anti-rabbit secondary antibody (1:200 dilution; Vector Laboratories, Burlingame, USA; 18hr) and avidin-biotin complex (1:100, Elite ABC kits; Vector Laboratories; USA; $4 \mathrm{hr}$ ). The chromogen was a $0.05 \%$ solution of 3 '-3'-diaminobenzidine (DAB) and $0.1 \mathrm{M}$ acetate imidazole buffer ( $\mathrm{pH} 7.4$ ) with $0.1 \% \mathrm{H}_{2} \mathrm{O}_{2}$. We fixed the $D A B$ reaction time to 60 s after addition of the chromogen solution, since at 70 s the proportion of brown precipitates obtained by peroxidase catalysed reaction reached a plateau. Thus protocol adheres to the Beer-Lambert law and ensure that the DAB labeling to identify TH-ir dopaminergic neurons is consistent. The dilution and washing, were done with $0.01 \mathrm{M}$ PBS containing $0.1 \%$ Triton X-100 (0.01M PBST, pH 7.4). In the negative controls, the primary antibody was replaced with the dilution buffer $[28,29,16]$.

\subsection{Stereology based analysis:}

Stereological quantification of TH-immunoreactive (TH-ir) DA neurons was performed using optical fractionator probe [30, 28, 31, 16]. On every sixth midbrain section (for P14, P18, and P22), the SN was delineated as described by Fu et al. [32] using a 4X objective of Olympus BX61 Microscope (Olympus Microscopes, Japan) equipped with Stereolnvestigator (Version 8.1, Micro-brightfield Inc., Colchester, USA). For P2, P6 and P10 specimens, every third section was chosen. We carefully excluded the VTA during quantification as it was located more dorso-medial to the substantia nigra [32]. The parabrachial pigmented nucleus segregated the SN and VTA. The red nucleus is furthermoredorso-medial to VTA and has a characteristic circular appearance. Its parvocellular and magnocellular neurons rarely or almost never stained for $\mathrm{TH}$, hence were easily excluded from quantification. Further, the retrorubral dopaminergic neurons that are present much caudally [33] were also not included for stereological evaluation. We counted the TH-ir cells using high power objective (100X), with a regular grid interval of $22500 \mu \mathrm{m}^{2}(x=150 \mu \mathrm{m}, \mathrm{y}=150 \mu \mathrm{m})$ and counting frame of size $3600 \mu \mathrm{m}^{2}(x=60 \mu \mathrm{m}, \mathrm{y}=60 \mu \mathrm{m})$. A guard zone of $4 \mu \mathrm{m}$ was implied on both sides resulting in an optical dissector of $17 \mu \mathrm{m}$. Quantification was performed in both hemispheres and pooled to derive total numbers.

The nigral volume was measured by principles of contour planimetry by delineating the nigra with 10X objective of Olympus BX61 Microscope (Olympus Microscopes, Japan) during stereological quantification. Evaluation interval, section thickness and grid spacing were identical to that of the parameters for stereological estimates of neuronal numbers. Besides, we qualitatively evaluated the ventral midbrain by light microscopy (4X, Leica DM 750$)$ at different time points, to derive the developmental time-point of attaining adult architecture.

\subsection{Densitometry based image analysis and Morphometry:}

High magnification (40X) images non-overlapping images of TH-ir DA neurons of SNpc were analysed offline for cellular TH expression using Q Win V3 (Leica Systems, Germany). A cumulative mean was derived after sampling approximately 150-200 DA neurons/animal. The values were expressed on an optical density scale of $0-255$, where ' 255 ' equalled intense staining. Similarly, for soma size, around 150 neurons per animal were sampled for P2-P10, and around 200 cells for P14-P22. The cumulative values were expressed in micrometre square $[14,16]$.

\subsection{TUNEL and TH co-labelling assay:}

We used a commercially available TUNEL kit (4823-30-K, Trivigen, USA) as per manufacturer's instructions, to detect apoptotic nuclei. Briefly, hydrated tissue sections were equilibrated with NeuroPore ${ }^{\mathrm{TM}}$ solution $(30 \mathrm{~min})$, followed by washing and immersion in TdT labeling buffer. The sections were incubated with labelling reaction mix in a humid chamber ( $2 \mathrm{hr}$ ) following which the reaction was terminated with Tdt stop buffer. The sections were then labelled with StrepHRP solution. The staining was visualized using $0.05 \%$ solution of $3^{\prime}-3^{\prime}$-diaminobenzidine (DAB) in $0.1 \mathrm{M}$ acetate imidazole buffer; $\mathrm{pH} 7.4$ and $0.1 \% \mathrm{H}_{2} \mathrm{O}_{2}$ with nickel ammonium sulfate enhancement. Thereafter, the sections were stained for TH, by immunoperoxidase protocol, to confirm that the assessment of apoptosis was being performed within the SNpc[16]. Finally, the sections were dehydrated, cleared, and cover-slipped using DPX. PBST (0.01 M, pH 7.4) was used as both working and washing buffer. For negative controls, the primary antibody was omitted. 


\subsection{Immunofluorescence staining:}

A sequential immunostaining protocol was performed to study the expression of AIF (1:200, SC-9416, Santa Cruz Biotechnology Inc, USA) and caspase-3 (1:200, SC-7148, Santa Cruz Biotechnology Inc, USA) as well as GDNF (1:200, SC-328, Santa Cruz Biotechnology Inc, USA) co-labelling with TH [16, 34]. Briefly, the sections were equilibrated (0.1M PBS, $\mathrm{pH} 7.4$ ) and blocked for $1 \mathrm{~h}$ in $3 \% \mathrm{BSA}$. Thereafter, the sections were incubated with the primary antibody (48 hr at $\left.4^{\circ} \mathrm{C}\right)$. This was followed by incubation with appropriate secondary antibodies i.e. Cy3-conjugated (1:200; C2821 or C2181; Sigma Aldrich, USA), FITCconjugated (1:200; F7367 or F7512, Sigma Aldrich, USA) or Cy5-conjugated secondary antibodies (1:200; AP192SA6; Merck Millipore, USA; 17 hrs at $4^{\circ} \mathrm{C}$ ). Similar immunolabeling steps were followed for the subsequent sequential staining. We used $0.01 \mathrm{M} \mathrm{PBST}$ (pH 7.4) as both working and washing buffer. Negative controls sections were incubated with only dilution buffer. Sections were mounted using Vectashield hard set mounting medium (H-400; Vector Laboratories, USA).

\subsection{Quantification of immunofluorescence intensity by image analysis:}

The immunofluorescence-labelled images of different sub-regions of SNpc were captured using laser scanning confocal microscope with the 20X objective at an optical zoom of two (DMIRE-TCS Leica, Germany). The intensity levels were used as a semi-quantitative measure of protein expression, using the inbuilt software [16]. Around 150-200 neurons/animal were sampled to derive cumulative mean. The excitation frequencies used were 488nm for FITC, 514nm for Cy3 and 633nm for Cy5. Emission band widths of 495-540nm for FITC, 550-620nm for Cy3, and 649-666 nm for Cy5 were maintained to avoid any overlap of emission frequencies. The striatum was photographed with 10X objective at a constant PMT voltage of 537 [34, 35].

\subsection{Statistical Analysis:}

The data was analysed using two-way ANOVA followed by Tukey's post hoc test. The values were stated as mean \pm SD and a p-value lower than 0.05 was considered significant.I

\section{Results:}

\subsection{Maturation of nigral architecture:}

The SNpc and pars reticulata (SNpr) were indistinguishable across the strains at P2 (Fig. 1a1- d1) as described earlier[36]. The DA neurons were randomly distributed throughout the ventral midbrain and occasional clusters were noted along the midline between P2 and P6. Thus till P6 we did not parcellate them as SNpc or SNpr, but considered them as a single entity, i.e. substantia nigra (SN). A gradual distinction between the two tiers was achieved after P6 (Fig. 1, a2, - d2). By P10 the SNpc DA neurons were identifiable (Fig. 1a3-d3). A clear adult architecture i.e. a compact band of DA neurons rich SNpc was observed at P14 in CD-1 (Fig. 1b4) and the crossbreds (Fig. c4-d4), whereas this discrimination was relatively delayed in C57BL/6J and appeared at P18 (Fig. 1a4). Qualitative observations of different nigral subsections showed that, the DA neurons in the lateral nigra appeared at P14 in C57BL/6J compared to appearance at P10 in the other strains (Fig. 1b3-a4, arrows).

\subsection{Differences in numbers of DA neurons during postnatal development:}

The C57BL/6J mice had significantly fewer TH -IR nigral neurons when compared to CD-1 and the crossbreds at P2 (Fig. 2a, Table 1, P2,

$\mathrm{p}<0.0001 \mathrm{C} 57 \mathrm{BL} / 6 \mathrm{~J}$ V/s CD-1, F1X1 \& F1X2). The numbers increased significantly thereafter in all the strains and the maximal increase was noted from P6 to P14 (Fig. 2a). During all the stages studies, the differences between C57BL/6J and rest of the strains were notable.

Table 1 Table listing the number of dopaminergic neurons at each stage and the $\%$ difference. ${ }^{* \star * *} \mathrm{p}<0.0001,{ }^{* \star *} \mathrm{p}<0.001,{ }^{* *} \mathrm{p}<0.01,{ }^{\star} \mathrm{p}<0.05$

\begin{tabular}{|c|c|c|c|c|c|c|c|c|}
\hline \multirow[t]{3}{*}{ Time-points } & \multicolumn{8}{|l|}{ Mice strains } \\
\hline & \multicolumn{2}{|l|}{ C57BL/6J } & \multicolumn{2}{|l|}{ CD-1 } & \multicolumn{2}{|l|}{$\mathrm{F} 1 \mathrm{X} 1$} & \multicolumn{2}{|l|}{$\mathrm{F} 1 \mathrm{X} 2$} \\
\hline & $\begin{array}{l}\text { Number } \\
\text { (Mean } \pm \text { SD) }\end{array}$ & $\begin{array}{l}\% \\
\text { change }\end{array}$ & $\begin{array}{l}\text { Number } \\
\text { (Mean } \pm \text { SD) }\end{array}$ & $\begin{array}{l}\% \\
\text { change }\end{array}$ & $\begin{array}{l}\text { Number } \\
\text { (Mean } \pm \text { SD) }\end{array}$ & $\begin{array}{l}\% \\
\text { change }\end{array}$ & $\begin{array}{l}\text { Number } \\
\text { (Mean } \pm \text { SD) }\end{array}$ & $\begin{array}{l}\% \\
\text { change }\end{array}$ \\
\hline Postnatal day (P) 2 & $7079 \pm 908$ & - & $9921 \pm 303$ & - & $10783 \pm 739$ & - & $11084 \pm 502$ & - \\
\hline P6 & $7603 \pm 744$ & 7.4 & $12651 \pm 930$ & $27.5^{\star \star \star}$ & $10909 \pm 720$ & 1.2 & $12053 \pm 591$ & 8.7 \\
\hline P10 & $10954 \pm 981$ & $44.4^{\star \star \star \star}$ & $12815 \pm 1448$ & 1.3 & $12598 \pm 1125$ & 15.5 & $12843 \pm 1183$ & 6.6 \\
\hline P14 & $13382 \pm 365$ & $22.2^{\star \star}$ & $15352 \pm 712$ & 19.8 ** & $15612 \pm 976$ & $23.9 * \star \star \star$ & $15580 \pm 1101$ & $21.3^{\star \star \star \star}$ \\
\hline P18 & $10552 \pm 1351$ & $-21.1^{\star \star \star \star}$ & $14229 \pm 1980$ & -7.3 & $15130 \pm 647$ & -3.1 & $15312 \pm 481$ & -1.72 \\
\hline P22 & $11236 \pm 961$ & 6.5 & $15369 \pm 1519$ & 8.0 & $15936 \pm 720$ & 5.3 & $16580 \pm 1258$ & 8.3 \\
\hline
\end{tabular}


Table 2

Table listing the volume of substantia nigra pars compacta at each stage and the \% difference in change. *Significant change denoting the critical developmental time points. ${ }^{*} \mathrm{p}<0.05$

\begin{tabular}{|c|c|c|c|c|c|c|c|c|}
\hline \multirow[t]{3}{*}{ Time-points } & \multicolumn{8}{|l|}{ Mice strains } \\
\hline & C57BL/6J & & CD-1 & & F1X1 & & $\mathrm{F} 1 \mathrm{X} 2$ & \\
\hline & $\begin{array}{l}\text { Volume }\left(\mathrm{mm}^{3}\right) \\
(\text { Mean } \pm \mathrm{SD})\end{array}$ & $\begin{array}{l}\% \\
\text { change }\end{array}$ & $\begin{array}{l}\text { Volume }\left(\mathrm{mm}^{3}\right) \\
(\text { Mean } \pm \mathrm{SD})\end{array}$ & $\begin{array}{l}\% \\
\text { change }\end{array}$ & $\begin{array}{l}\text { Volume }\left(\mathrm{mm}^{3}\right) \\
(\text { Mean } \pm \mathrm{SD})\end{array}$ & $\begin{array}{l}\% \\
\text { change }\end{array}$ & $\begin{array}{l}\text { Volume }\left(\mathrm{mm}^{3}\right) \\
(\text { Mean } \pm \mathrm{SD})\end{array}$ & $\begin{array}{l}\% \\
\text { change }\end{array}$ \\
\hline
\end{tabular}

\begin{tabular}{|c|c|c|c|c|c|c|c|c|}
\hline Postnatal day $(P) 2$ & $0.22 \pm 0.03$ & - & $0.29 \pm 0.003$ & - & $0.30 \pm 0.01$ & - & $0.29 \pm 0.003$ & - \\
\hline P6 & $0.24 \pm 0.02$ & 11.79 & $0.37 \pm 0.02$ & $27.35^{\star}$ & $0.31 \pm 0.01$ & 5.49 & $0.32 \pm 0.01$ & 9.11 \\
\hline P10 & $0.29 \pm 0.02$ & 20.95 & $0.33 \pm 0.03$ & -9.13 & $0.36 \pm 0.03$ & 15.89 & $0.35 \pm 0.05$ & 11.00 \\
\hline P14 & $0.30 \pm 0.02$ & 3.56 & $0.37 \pm 0.02$ & 9.81 & $0.41 \pm 0.02$ & 12.19 & $0.41 \pm 0.05$ & 15.88 \\
\hline P18 & $0.29 \pm 0.03$ & -4.86 & $0.37 \pm 0.03$ & 1.84 & $0.40 \pm 0.02$ & -2.38 & $0.37 \pm 0.02$ & -8.12 \\
\hline P22 & $0.34 \pm 0.06$ & 18.17 & $0.36 \pm 0.08$ & -2.35 & $0.41 \pm 0.02$ & 3.98 & $0.41 \pm 0.04$ & 8.48 \\
\hline
\end{tabular}

Thereafter a drastic fall in numbers was noted till P18, selectively in C57BL/6J (Fig. 2a, C57BL/6J, ***p<0.001, P14 v/s P18). The reduction stabilized at P22 (Fig. 2a, C57BL/6J), and the numbers were comparable with the adult mice described earlier [16]. Despite the reduction between P14-P18, the numbers at P22 were significantly higher than those at P2. Interestingly, the CD-1 and crossbreds retained their numbers from P14 to stabilize with relatively more DA neurons at P18 and P22 (Fig. 2a). At P22, the CD-1 and crossbreds had approximately 40\% more DA neurons than C57BL/6J (Table 1; Fig. 2a,

$\mathrm{p}<0.0001, \mathrm{C} 57 \mathrm{BL} / 6 \mathrm{~J}$ v/s CD-1, F1X1 \& F1X2). Effectively the quantitative differences between the strains persisted throughout the development.

\subsection{Alterations in nigral volume:}

Evaluation of nigral volume revealed two distinct observations. First that, a notable increase occurs in the nigral volume during development i.e. from P2 to P22 across all the mice strains (Fig. 2b). Secondly, at P2 and throughout development, the SN of C57BL/6J was much smaller than CD-1 and the crossbreds (Fig. 2b, $\$ \$$ p < 0.001, C57BL/6J v/s CD-1, F1X1 \& F1X2; differences at P2: C57BL/6J v/s CD-1: 40.15\%; v/s F1X1: 52.32 \%; v/s F1X2: 56.58 \%). A significant

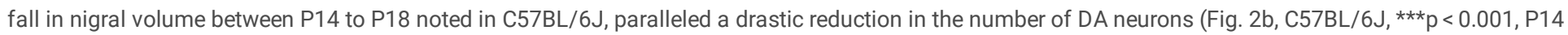
$\mathrm{V} / \mathrm{s} \mathrm{P} 18)$. Thus the nigral volume was significantly higher in CD-1 and crossbreds and stabilized at P14, whereas in C57BL/6J it reduced till P18 and stabilized thereafter (Fig. 2b). Essentially the CD-1 and crossbreds possessed significantly voluminous SN at P22 than the C57BL/6J (Fig. 2b, $\$ \$ p<0.01, v / s$ CD-1, FIX1 and F1X2).

\subsection{Differences in 'density per unit area' of DA neurons:}

The DA neuronal density in the CD-1, F1X1 and F1X2 strains, remained unchanged throughout development (Fig. 2c; Table 3). Interestingly, in the C57BL/6J, the density increased gradually to peak at P14 (Fig. 2c, C57BL/6J, **p $<0.01$ P6 v/s P10, **p $<0.01$ P10 v/s P14; Table 3) and stabilized by P22 but was significantly lesser than F1X2 (Fig. 2C, P22, $\$ \$ p<0.01, C 57 B L / 6 J$ v/s F1X2). Yet it was comparable to other strains.

Table 3

Table listing the tyrosine hydroxylase expression (staining intensity on a scale of 0-255) at each stage and the \% difference in change. ${ }^{*}$ Significant change denoting the critical developmental time points. ${ }^{* \star *} p<0.0001,{ }^{* *} p<0.001,{ }^{* *} p<0.01,{ }^{*} p<0.05$

\begin{tabular}{|c|c|c|c|c|c|c|c|c|}
\hline \multirow{4}{*}{$\begin{array}{l}\text { Time-points } \\
\text { Postnatal day (P) } 2\end{array}$} & \multicolumn{8}{|l|}{ Mice strains } \\
\hline & \multicolumn{2}{|l|}{ C57BL/6J } & \multicolumn{2}{|l|}{ CD-1 } & \multicolumn{2}{|l|}{$\mathrm{F} 1 \mathrm{X} 1$} & \multicolumn{2}{|l|}{ F1X2 } \\
\hline & Intensity & $\%$ & Intensity & $\%$ & Intensity & $\%$ & Intensity & $\%$ \\
\hline & $($ Mean $\pm S D)$ & change & $($ Mean $\pm S D)$ & change & $($ Mean $\pm S D)$ & change & $($ Mean $\pm S D)$ & change \\
\hline P2 & $191.39 \pm 6.74$ & - & $218.22 \pm 5.31$ & - & $185.44 \pm 8.43$ & - & $211.11 \pm 3.68$ & - \\
\hline P6 & $185.99 \pm 8.14$ & -2.82 & $204.65 \pm 13.58$ & -6.22 & $196.32 \pm 2.34$ & 5.86 & $195.28 \pm 3.12$ & -7.50 \\
\hline P10 & $163.33 \pm 11.17$ & $-12.18^{\star \star}$ & $193.24 \pm 11.13$ & -5.58 & $190.79 \pm 7.63$ & -2.82 & $186.98 \pm 11.43$ & -4.25 \\
\hline P14 & $145.92 \pm 4.97$ & $-10.66^{\star}$ & $152.70 \pm 10.00$ & 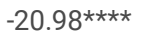 & $171.88 \pm 5.20$ & $-9.91^{*}$ & $172.84 \pm 6.30$ & -7.56 \\
\hline P18 & $158.73 \pm 11.59$ & 8.78 & $143.93 \pm 5.86$ & -5.75 & $157.23 \pm 3.52$ & -8.53 & $164.02 \pm 2.28$ & -5.10 \\
\hline P22 & $133.23 \pm 12.26$ & $-16.06^{\star \star \star}$ & $159.64 \pm 7.85$ & 10.92 & $160.56 \pm 1.74$ & 2.12 & $162.77 \pm 8.19$ & -0.76 \\
\hline
\end{tabular}


Table 4

Comparison and percentage differences in volume of $\mathrm{SN}$ and tyrosine hydroxylase $(\mathrm{TH})$ expression in different strains at critical time points. ${ }^{* \star \star \star} \mathrm{p}<$ $0.0001, * \star \star p<<0.001, * \star p<0.01,{ }^{*} p<0.05$

\begin{tabular}{|c|c|c|c|c|}
\hline \multirow[t]{3}{*}{ Comparison between strains } & \multicolumn{4}{|c|}{ Time points } \\
\hline & \multicolumn{2}{|l|}{ P2 (\%) } & \multicolumn{2}{|l|}{ P14(\%) } \\
\hline & Volume & TH & Volume & TH \\
\hline C57BL/6J v/s CD-1 & $31.81^{\star \star}$ & $14.01^{\star \star \star \star}$ & $23.33^{\star \star}$ & 4.64 \\
\hline C57BL/6J v/s F1X1 & $36.36^{\star *}$ & 3.10 & $36.66^{\star \star \star}$ & 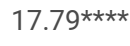 \\
\hline C57BL/6J v/s F1X2 & $31.81^{\star \star}$ & $10.30 * *$ & $36.66^{\star \star *}$ & $18.48^{\star \star * *}$ \\
\hline CD-1 v/s F1X1 & 3.44 & $15.02^{\star \star \star \star}$ & 10.81 & $12.56^{\star \star}$ \\
\hline CD-1 v/s F1X2 & 0.00 & 3.25 & 10.81 & $13.18^{\star \star}$ \\
\hline F1X1 v/s F1X2 & 3.33 & $13.84^{\star \star \star \star}$ & 0.00 & 0.55 \\
\hline
\end{tabular}

\subsection{TH expression during development and cellular morphology:}

Across all strains, the DA neurons increased in size with developmental age (Fig. 3a1-d5; e). A closer comparison revealed that, the P2 neurons of both the parent strains, i.e., C57BL/6J and CD-1 were much larger than the crossbreds (Fig. 3, compare a1, b1 with c1 \& d1; P2, \$\$p < 0.01, C57BL/6J \& CD-1 v/s F1X1 \& F1X2). All the strains showed considerable increase in the soma size from P2-P10 (Fig. 3e, C57BL/6J, **p<0.01, P2 v/s P10; F1X1, \#\#\#p<0.001, F1X2, @@@@p $<0.001, \mathrm{P} 2 \mathrm{v} / \mathrm{s} \mathrm{P} 10)$. Interestingly, the soma sizes were comparable at $\mathrm{P} 10$, in all the strains, with a clear demarcation between the nucleus and cytoplasm. Thereafter, in C57BL/6J they continued to increase in size (Fig. 3e, C57BL/6J, **p < 0.01, P18 v/s P22) resulting in a larger soma than the rest, at P22 (Fig. 3e, $\$ \$ \$ p<0.001, C 57 B L / 6 J$ v/s CD-1, F1X1 \& F1X2).

The CD-1 and F1X2 showed relatively higher TH expression at P2 (Fig. 3f). Interestingly, unlike other observations, it was highest at P2 compared to the other stages (Fig. 3f). The expression stabilized to its adult levels at P14 in CD-1 and crossbreds (Fig. 3f), while at P22 in C57BL/6J (Fig. 3f, C57BL/6J, ***p<0.001, $\mathrm{P} 18 \mathrm{v} / \mathrm{s} \mathrm{P} 22)$.

In view of the appreciable differences in the soma size and the TH expression amongst strains, we quantified TH expression per unit soma area. TheF1X2 mice nigra showed higher TH expression/unit soma area at P2 compared to C57BL/6J (Fig. 3g, P2,

$\mathrm{p}<0.0001, \mathrm{C} 57 \mathrm{BL} / 6 \mathrm{~J}$ v/s F1X2). A significant decline in the ratio was noted until P10 in all the strains. It stabilized at P14 in CD-1, F1X1 and F1X2, whereas at P22 in C57BL/6J with a further decrement (Fig. 3g, C57BL/6J, **p<0.01, P18 v/s P22).

\subsection{Alterations in developmental apoptosis and cell death markers:}

Developmental cell death was correspondingly evaluated, by TUNEL, at P2, P6, P10, P14, P18 and P22. TH immunoreactive (brown) cells labelled for TUNEL reaction (black) in the nucleus were identified as apoptotic DA neurons (Fig. 4. Ab). TUNEL-ir cells that were TH negative, but present within the nigral region were also considered (Fig. 4. Aa). A positive control (Fig. 4. Ac) showed TUNEL reaction in almost all cells in the field. Peak apoptosis was noted at P2 and P14 (Fig. 4B \& 4C, P14 *p< 0.05 C57BL/6J vs. F1X2) across the strains. The C57BL/6J had more TUNEL-TH co-labelled neurons, and persisted till P22; while in the CD-1 and the crossbreds, they subsided by P14.

The caspase-3 and AIF expression was evaluated exclusively in TH co-labelled neurons so as to assess the alterations in the surviving dopaminergic neurons. At P2, AlF expression was higher in both the parent strains (Fig. 4E, ${ }^{\mathrm{P}}<0.05$; C57BL/6J vs F1X1 and CD-1 vs F1X1). At P14, it was much higher in C57BL/6J

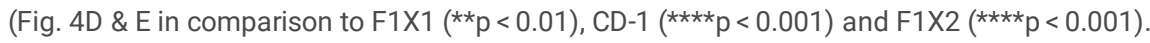

Caspase-3 expression was comparable in all the study groups at P2. The differences began to be appreciable at P14 (Fig. 4D) when it was higher in C57BL/6J (Fig. 4F; ${ }^{*}$ < 0.05 C57BL/6J vs. F1X2; ${ }^{*} p<0.05$ CD-1 vs. F1X2) as also in F1X1 (**p<0.01 vs F1X2) that persisted till P22 in C57BL/6J (C57BL/6J vs CD-1, *p

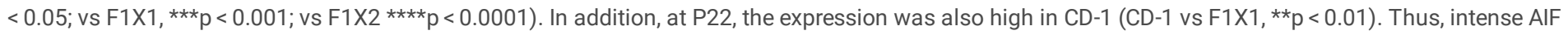
expression was noted at P14 (Fig. 4E) whereas for caspase-3 expression, it was relatively higher at P22 in C57BL/6J (Fig. 4F).

\subsection{GDNF expression in striatum and nigra:}

A significant upregulation in GDNF expression was noted in C57BL/6J between postnatal days 2 and 14, in the striatum (Fig. 5. A\&B; P2 *p< 0.05 C57BL/6J vs. CD-1; P2 **p $<0.01$ C57BL/6J vs. F1X2; C57BL/6J **p< 0.01 P2 vs. P14; P14 *p $<0.05$ C57BL/6J vs. F1X1). The basal GDNF was high in CD-1 and F1X2 at $\mathrm{P} 2$, and also at $\mathrm{P} 14$. In contrast, in the nigra, its expression reduced between $\mathrm{P} 2$ and $\mathrm{P} 14$ in all the strains. (Figure. $5 C \& D$. $\mathrm{P} 2$ ** $\mathrm{p}<0.01 \mathrm{CD}-1$ vs $\mathrm{F} 1 \mathrm{X} 2 ; \mathrm{P} 2{ }^{\star} \mathrm{P}<$ 0.05 F1X1 vs. F1X2; C57BL/6J *** $p<0.001$ P2 vs. P14; CD-1**p<0.01 P2 vs. P14; F1X2 *p<0.05 P2 vs P14).

\section{Discussion:}

A few neuropsychiatric diseases like autism and attention deficit hyperactive disorder etc. are thought to be neurodevelopmental disorders while others like Huntington's, Alzheimer's, Parkinson's disease are designated as adult or elderly onset disorders [37-41]. It is being increasingly recognized that deregulation of developmental neuronal apoptosis or glial death may result in functional deficits and associated diseases in the later years of life [42]. In the absence of

Page 6/15 
human tissues for analysis, animal models are valuable resources for mechanistic explanations of a disease. Ours is the first study using unbiased stereology on developing nigra that compares the developmental trajectories of nigral DA neurons in two distinct mice strains and the F1 progeny of their crossbreds. The studies were conducted in MPTP-sensitive C57BL/6J, MPTP resistant CD-1 mice and the F1 generation of their reciprocal crossbreds. Our model offers the advantage of "no use of neurotoxins", since most other studies on PCD relied on chemical lesions to investigate target dependence in development.

The first two postnatal weeks are crucial for the rodent midbrain DA system, for being associated with culmination of neuronal migration, maturation of perikarya, extension of axons and their terminal differentiation, which occurs alongside the apoptotic death of neurons that fail to mature [43, 25, 44, 26]. Stressors during this period prime the DA system to subsequent insults like prenatal stress, maternal separation, ischemia, hypoxia and excitotoxicity etc. resulting in the delayed attainment of DA phenotype [45], reduction in the number of DA neurons, exaggerated response to neurotoxins [46, 47] and affect the DA neurotransmission at adulthood [48]. In fetal non-human primates [24] peak PCD of DA neurons occurs at E80 and approximately at mid-gestation in humans, when approximately $50 \%$ neurons are pruned. The time period P2 in rats equates with E79/80 in monkeys [24], thus P2 in mice is a critical window of vulnerability and protective modalities could be developed if the relevant molecular underpinnings are understood.

The clusters of TH-ir neurons found along the midline during early postnatal development i.e. P2 and P6 probably represent the migrating neurons or other dopaminergic clusters. The gradual increase in numbers till P14 point at the culmination of neuronal migration [49-51], or addition of TH-ir neurons by postnatal neurogenesis $[52-54,49]$. The third likelihood is that progressively more neurons show detectable levels of TH expression i.e. they attain DA phenotype $[55,56,45]$. These factors reduce the likelihood of extensive cell loss during this phase, thus maintaining the steady increase in numbers. In an earlier study using unbiased stereology, Jackson-Lewis et al. (2000) also reported a gradual increase in nigral dopaminergic neurons till P14. However, the small decline in the numbers after P14 observed in our study was contrasted by absence of cell loss in their study. Our observation is corroborated by the findings of Oo and Burke [25], who showed a smaller second peak of dopaminergic neuronal loss around P14. The data of Jackson-Lewis et al. [23] represent cumulative results of two different mice strains i.e. C57BL/6J and CD-1, which may underlie the discrepancy. The delay in attainment of adult nigral architecture in $\mathrm{C} 57 \mathrm{BL} / 6 \mathrm{~J}$ i.e. at P18, may be attributed to the ongoing cell loss vis-à-vis the early maturation at P14 in CD-1 and the crossbreds. Our observations on C57BL/6J, match those of Oo and Burke [25], who showed two peaks of loss i.e. at P2 and P14 in rats, proposing a biphasic nature of programmed cell death. We propose an additional minor peak at P22 in C57BL/6J, complemented by TUNEL reaction, caspase-3 expression and reduction in TH-ir dopaminergic neurons. Both caspase-mediated and caspase-independent cell death pathways, associated with mitochondria and endoplasmic reticulum respectively, work in unison to cause neurodegeneration[57]. The enhancement of AIF corroborates with the role of caspase independent cell death in developing human midbrain [58]. Elevated AIF expression at P14 in addition to high caspase-3 expression at P22, corroborated by TUNEL-expression, further illustrate the alliance between the two cell death pathways in the instance of DA neurons.

Classical studies suggest that GDNF protects nigral neuron from apoptosis [59,60]. Recent studies consider it as a potent therapeutic for PD [61, 62]. It is expressed in the striatum and reaches SNpc through retrograde transport[63]. Therefore, its mRNA synthesis and protein expression during striatal development are critical[64]. The upregulation of GDNF in the striatum from day 2 to day 14, in contrast to reduced expression in the SNpc at analogous stages, compares well with earlier studies[64, 65] and it may be associated with the refinement of the nigrostriatal connections. GDNF expression at P2 may be paracrine/nigral in origin, since the nigro-striatal connections are yet not formed. At later stages, the source may switch to striatum. The higher levels in the crossbreds suggest better neuroprotection in them, which could be conjectured during nigral development in the Anglo-Indians, scaling up their dopaminergic reserve. It might be worthwhile to examine the early embryonic periods and develop preventative strategies.

Cellular hypertrophy following second peak of apoptosis noted exclusively in C57BL/6J may be a physiological process corresponding to the expansion of nerve terminals, also seen in other amine systems [49,66-68]. Alternatively it may be a predisposing factor; since larger neurons are vulnerable to degeneration [69]. Hypertrophy of DA neurons in aging human nigra was considered as a compensation for sub-threshold neurodegeneration [10] and its absence as a marker for resilience [12]. The gradual decrease in cellular TH over development alongside an increase in soma area, suggests that overall dopamine synthesis remains stable through development. Amongst the strains, F1X2 showed best preservation of TH levels.

A correlation between the nigral volume and the neuronal numbers through development and across strains indicates that volume can be an indirect measure of DA neuronal number. Nigral volumetry by MRI is a diagnostic tool for PD, based on a similar premise. The striatal volume varies in healthy individuals [70, 71] and imparts differential susceptibility to psychiatric disorders [72-74]. Anthropometric studies suggest that children with smaller head circumference and cerebral volume may develop Huntington's disease [37] reflecting the developmental origin of the disease. Cognitive capabilities were better protected in Alzheimer's disease patients with relatively larger head circumference [75]. Therefore, nigral volumetry may be a valuable tool to identify the predisposed individuals/populations.

A hypothetical division of the postnatal period in three phases reveals that the second phase that defines the neuronal numbers is more critical. Such differences may be envisioned in the Caucasian, Asian-Indians, and their admixed population imparting them varying degrees of susceptibility to develop PD $[9,12,11,6,15,34,35]$.

Finally, the findings of fewer neurons throughout development in C57BL/6J nigra; posit the presence of excessive endogenous toxins or pro-apoptotic factors at these stages. This possibility was strengthened by corresponding high levels of caspase-3 and AIF. The higher cellular packing density at P14 in C57BL/6J may represent increased competition for trophic factors. Whereas, minimal loss of DA cells, higher GNDF and controlled expression of pro-apoptotic factors in CD-1 and the crossbreds, hint at better endogenous milieu. Developmental apoptosis sculpts aberrant neural connections[76, 77]to regulate the final neural numbers in adult multicellular organisms $[78,79]$. Since both the mice strains are non-transgenic and genetically distinct, we hypothesize that genetic constitution may predispose individuals or populations even in absence of major mutations. In late eighties, Fahn [5] hypothesised that the brain wiring during development may influence the number of neurons at birth and other cellular features which may be unique to the individuals, making them either vulnerable or resilient to PD. He also proposed that the metabolic processes in the brain may govern vulnerability to develop PD [5]. Both these hypotheses hereby stand 
validated, hinting at the developmental origin of vulnerability to MPTP. It may therefore be possible that susceptibility to PD originates during nigral development in humans.

\section{Declarations:}

\section{Declarations}

Ethics approval and consent to participate: the study was approved by NIMHANS Institutional Animal Ethics committee (AEC/50/312/N.P.). Since this study presents no human data, the "consent to participate" is not applicable.

Consent for publication: All authors have approved the work described in this manuscript and consented for its submission and publication.

Availability of data and materials: The data will be made available upon reasonable request. We purchased commercially available antibodies hence we do not have any biological material to share.

Competing interests: The authors declare that the research was conducted in the absence of any commercial or financial relationships with any company that could be construed as a potential conflict of interest.

Funding: The study was funded by Science and Engineering Research Board, DST, Govt. of India to PAA (No. SR/SO/HS-0121/2012). VDJ was a NIMHANS JRF and HY was a University Grants Commission (UGC) JRF.

Author's contributions: PAA conceptualised the project and obtained funds. VDJ, HY \& PAA performed the experiments and analysed the data. VDJ, HY, TRR \& PAA wrote the manuscript. PAA edited the final version. All authors approved the final version of the manuscript for publication.

Acknowledgement: Authors are grateful to Dr. G.H. Mohan, Co-Head, Animal Care and Resource Center/Head Veterinarian for providing breeding pairs of CD-1 mice to establish the colonies.

\section{References}

1. Fearnley JM, Lees AJ (1991) Ageing and Parkinson's disease: substantia nigra regional selectivity. Brain 114(Pt 5):2283-2301

2. Ma SY, Rinne JO, Collan Y, Roytta M, Rinne UK (1996) A quantitative morphometrical study of neuron degeneration in the substantia nigra in Parkinson's disease. Journal of the neurological sciences 140(1-2):40-45

3. Kordower JH, Olanow CW, Dodiya HB, Chu Y, Beach TG, Adler CH, Halliday GM, Bartus RT (2013) Disease duration and the integrity of the nigrostriatal system in Parkinson's disease. Brain 136(Pt 8):2419-2431. doi:10.1093/brain/awt192

4. Vidyadhara DJ, Lee JE, Chandra SS (2019) Role of the endolysosomal system in Parkinson's disease. J Neurochem 150(5):487-506. doi:10.1111/jnc. 14820

5. Fahn S (1989) The endogenous toxin hypothesis of the etiology of Parkinson's disease and a pilot trial of high-dosage antioxidants in an attempt to slow the progression of the illness. Ann N Y Acad Sci 570:186-196

6. Strickland D, Bertoni JM (2004) Parkinson's prevalence estimated by a state registry. Movement disorders: official journal of the Movement Disorder Society 19(3):318-323. doi:10.1002/mds.10619

7. von Campenhausen S, Bornschein B, Wick R, Botzel K, Sampaio C, Poewe W, Oertel W, Siebert U, Berger K, Dodel R (2005) Prevalence and incidence of Parkinson's disease in Europe. European neuropsychopharmacology: the journal of the European College of Neuropsychopharmacology 15(4):473-490. doi:10.1016/j.euroneuro.2005.04.007

8. Marras C, Beck JC, Bower JH, Roberts E, Ritz B, Ross GW, Abbott RD, Savica R, Van Den Eeden SK, Willis AW, Tanner CM (2018) Prevalence of Parkinson's disease across North America. NPJ Parkinsons Dis 4:21. doi:10.1038/s41531-018-0058-0

9. Chu Y, Kompoliti K, Cochran EJ, Mufson EJ, Kordower JH (2002) Age-related decreases in Nurr1 immunoreactivity in the human substantia nigra. J Comp Neurol 450(3):203-214. doi:10.1002/cne.10261

10. Cabello CR, Thune JJ, Pakkenberg H, Pakkenberg B (2002) Ageing of substantia nigra in humans: cell loss may be compensated by hypertrophy. Neuropathology applied neurobiology 28(4):283-291

11. Das SK, Misra AK, Ray BK, Hazra A, Ghosal MK, Chaudhuri A, Roy T, Banerjee TK, Raut DK (2010) Epidemiology of Parkinson disease in the city of Kolkata, India: a community-based study. Neurology 75(15):1362-1369. doi:10.1212/WNL.0b013e3181f735a7

12. Alladi PA, Mahadevan A, Yasha TC, Raju TR, Shankar SK, Muthane U (2009) Absence of age-related changes in nigral dopaminergic neurons of Asian Indians: relevance to lower incidence of Parkinson's disease. Neuroscience 159(1):236-245. doi:10.1016/j.neuroscience.2008.11.051

13. Naskar A, Mahadevan A, Philip M, Alladi PA (2019) Aging mildly affects dendritic arborisation and synaptic protein expression in human substantia nigra pars compacta. J Chem Neuroanat 97:57-65. doi:10.1016/j.jchemneu.2019.02.001

14. Jyothi HJ, Vidyadhara DJ, Mahadevan A, Philip M, Parmar SK, Manohari SG, Shankar SK, Raju TR, Alladi PA (2015) Aging causes morphological alterations in astrocytes and microglia in human substantia nigra pars compacta. Neurobiol Aging 36(12):3321-3333.

doi:10.1016/j.neurobiolaging.2015.08.024

15. Ragothaman M, Murgod UA, Gururaj G, Kumaraswamy SD, Muthane U (2003) Lower risk of Parkinson's disease in an admixed population of European and Indian origins. Movement disorders: official journal of the Movement Disorder Society 18(8):912-914. doi:10.1002/mds.10449 
16. Vidyadhara DJ, Yarreiphang H, Raju TR, Alladi PA (2017) Admixing of MPTP-Resistant and Susceptible Mice Strains Augments Nigrostriatal Neuronal Correlates to Resist MPTP-Induced Neurodegeneration. Mol Neurobiol 54(8):6148-6162. doi:10.1007/s12035-016-0158-y

17. Vidyadhara DJ, Yarreiphang H, Abhilash PL, Raju TR, Alladi PA (2016) Differential expression of calbindin in nigral dopaminergic neurons in two mice strains with differential susceptibility to 1-methyl-4-phenyl-1,2,3,6-tetrahydropyridine. J Chem Neuroanat. doi:10.1016/j.jchemneu.2016.01.001

18. Vidyadhara DJ, Sasidharan A, Kutty BM, Raju TR, Alladi PA (2019) Admixing MPTP-resistant and MPTP-vulnerable mice enhances striatal field potentials and calbindin-D28K expression to avert motor behaviour deficits. Behav Brain Res 360:216-227. doi:10.1016/j.bbr.2018.12.015

19. Seshadri A, Alladi PA (2019) Divergent Expression Patterns of Drp1 and HSD10 in the Nigro-Striatum of Two Mice Strains Based on their MPTP Susceptibility. Neurotox Res 36(1):27-38. doi:10.1007/s12640-019-00036-8

20. Bhaduri B, Abhilash PL, Alladi PA (2018) Baseline striatal and nigral interneuronal protein levels in two distinct mice strains differ in accordance with their MPTP susceptibility. J Chem Neuroanat 91:46-54. doi:10.1016/j.jchemneu.2018.04.005

21. Sailaja K, Gopinath G (1996) Ultrastructure of developing substantia nigra in humans. International journal of developmental neuroscience: the official journal of the International Society for Developmental Neuroscience 14(6):761-770

22. Sailaja K, Gopinath G (1994) Developing substantia nigra in human: a qualitative study. Developmental neuroscience 16(1-2):44-52

23. Jackson-Lewis V, Vila M, Djaldetti R, Guegan C, Liberatore G, Liu J, O'Malley KL, Burke RE, Przedborski S (2000) Developmental cell death in dopaminergic neurons of the substantia nigra of mice. J Comp Neurol 424(3):476-488

24. Morrow BA, Roth RH, Redmond DE Jr, Sladek JR Jr, Elsworth JD (2007) Apoptotic natural cell death in developing primate dopamine midbrain neurons occurs during a restricted period in the second trimester of gestation. Exp Neurol 204(2):802-807. doi:10.1016/j.expneurol.2007.01.009

25. Oo TF, Burke RE (1997) The time course of developmental cell death in phenotypically defined dopaminergic neurons of the substantia nigra. Brain research Developmental brain research 98(2):191-196

26. Burke RE (2003) Postnatal developmental programmed cell death in dopamine neurons. Ann N Y Acad Sci 991:69-79

27. Jiang P, Gan M, Yen SH, McLean PJ, Dickson DW (2017) Histones facilitate a-synuclein aggregation during neuronal apoptosis. Acta Neuropathol 133(4):547-558. doi:10.1007/s00401-016-1660-z

28. Suresh SN, Chavalmane AK, Yarreiphang DJV, Rai H, Paul S, Clement A, Alladi JP, Manjithaya PA R (2017) A novel autophagy modulator 6-Bio ameliorates SNCA/alpha-synuclein toxicity. Autophagy:0. doi:10.1080/15548627.2017.1302045

29. Sn S, Pandurangi J, Murumalla R, Dj V, Garimella L, Acharya A, Rai S, Paul A, Yarreiphang H, Pillai MS, Giridharan M, Clement JP, Alladi PA, Saiyed T, Manjithaya R (2019) Small molecule modulator of aggrephagy regulates neuroinflammation to curb pathogenesis of neurodegeneration. EBioMedicine. doi:10.1016/j.ebiom.2019.10.036

30. Baquet ZC, Williams D, Brody J, Smeyne RJ (2009) A comparison of model-based (2D) and design-based (3D) stereological methods for estimating cell number in the substantia nigra pars compacta (SNpc) of the C57BL/6J mouse. Neuroscience 161(4):1082-1090. doi:10.1016/j.neuroscience.2009.04.031

31. Suresh SN, Chavalmane AK, Pillai M, Ammanathan V, Vidyadhara DJ, Yarreiphang H, Rai S, Paul A, Clement JP, Alladi PA, Manjithaya R (2018) Modulation of Autophagy by a Small Molecule Inverse Agonist of ERRalpha Is Neuroprotective. Front Mol Neurosci 11:109. doi:10.3389/fnmol.2018.00109

32. Fu Y, Yuan Y, Halliday G, Rusznák Z, Watson C, Paxinos G (2012) A cytoarchitectonic and chemoarchitectonic analysis of the dopamine cell groups in the substantia nigra, ventral tegmental area, and retrorubral field in the mouse. Brain Struct Funct 217(2):591-612. doi:10.1007/s00429-011-0349-2

33. Yetnikoff L, Lavezzi HN, Reichard RA, Zahm DS (2014) An update on the connections of the ventral mesencephalic dopaminergic complex. Neuroscience 282:23-48. doi:10.1016/j.neuroscience.2014.04.010

34. Alladi PA, Mahadevan A, Shankar SK, Raju TR, Muthane U (2010) Expression of GDNF receptors GFRalpha1 and RET is preserved in substantia nigra pars compacta of aging Asian Indians. J Chem Neuroanat 40(1):43-52. doi:10.1016/j.jchemneu.2010.03.007

35. Alladi PA, Mahadevan A, Vijayalakshmi K, Muthane U, Shankar SK, Raju TR (2010) Ageing enhances alpha-synuclein, ubiquitin and endoplasmic reticular stress protein expression in the nigral neurons of Asian Indians. Neurochem Int 57(5):530-539. doi:10.1016/j.neuint.2010.06.018

36. Fu Y, Paxinos G, Watson C, Halliday GM (2016) The substantia nigra and ventral tegmental dopaminergic neurons from development to degeneration. J Chem Neuroanat 76 (Pt B):98-107. doi:10.1016/j.jchemneu.2016.02.001

37. Lee JK, Mathews K, Schlaggar B, Perlmutter J, Paulsen JS, Epping E, Burmeister L, Nopoulos P (2012) Measures of growth in children at risk for Huntington disease. Neurology 79(7):668-674. doi:10.1212/WNL.0b013e3182648b65

38. Panzer A, Viljoen M (2005) Supportive neurodevelopmental evidence for ADHD as a developmental disorder. Medical hypotheses 64(4):755-758. doi:10.1016/j.mehy.2003.12.060

39. Fatemi SH, Folsom TD (2009) The neurodevelopmental hypothesis of schizophrenia, revisited. Schizophr Bull 35(3):528-548. doi:10.1093/schbul/sbn187

40. Sullivan RM, Brake WG (2003) What the rodent prefrontal cortex can teach us about attention-deficit/hyperactivity disorder: the critical role of early developmental events on prefrontal function. Behav Brain Res 146(1-2):43-55

41. Weber K, Rockstroh B, Borgelt J, Awiszus B, Popov T, Hoffmann K, Schonauer K, Watzl H, Propster K (2008) Stress load during childhood affects psychopathology in psychiatric patients. BMC Psychiatry 8:63. doi:10.1186/1471-244x-8-63

42. Arya R, White K (2015) Cell death in development: Signaling pathways and core mechanisms. Semin Cell Dev Biol 39:12-19. doi:10.1016/j.semcdb.2015.02.001

43. Voorn P, Kalsbeek A, Jorritsma-Byham B, Groenewegen HJ (1988) The pre-and postnatal development of the dopaminergic cell groups in the ventral mesencephalon and the dopaminergic innervation of the striatum of the rat. Neuroscience 25(3):857-887

Page 9/15 
44. Antonopoulos J, Dori I, Dinopoulos A, Chiotelli M, Parnavelas JG (2002) Postnatal development of the dopaminergic system of the striatum in the rat. Neuroscience 110(2):245-256

45. Katunar MR, Saez T, Brusco A, Antonelli MC (2010) Ontogenetic expression of dopamine-related transcription factors and tyrosine hydroxylase in prenatally stressed rats. Neurotox Res 18(1):69-81. doi:10.1007/s12640-009-9132-z

46. Pienaar IS, Kellaway LA, Russell VA, Smith AD, Stein DJ, Zigmond MJ, Daniels WM (2008) Maternal separation exaggerates the toxic effects of 6hydroxydopamine in rats: implications for neurodegenerative disorders. Stress 11(6):448-456. doi:10.1080/10253890801890721

47. Mabandla MV, Russell VA (2010) Voluntary exercise reduces the neurotoxic effects of 6-hydroxydopamine in maternally separated rats. Behav Brain Res 211(1):16-22. doi:10.1016/j.bbr.2010.02.045

48. Rodrigues AJ, Leao P, Carvalho M, Almeida OF, Sousa N (2011) Potential programming of dopaminergic circuits by early life stress. Psychopharmacology 214(1):107-120. doi:10.1007/s00213-010-2085-3

49. Park M, Kitahama K, Geffard M, Maeda T (2000) Postnatal development of the dopaminergic neurons in the rat mesencephalon. Brain Dev 22(Suppl 1):S38-S44

50. Lieb K, Andersen C, Lazarov N, Zienecker R, Urban I, Reisert I, Pilgrim C (1996) Pre- and postnatal development of dopaminergic neuron numbers in the male and female mouse midbrain. Brain research Developmental brain research 94(1):37-43

51. Kawano H, Ohyama K, Kawamura K, Nagatsu I (1995) Migration of dopaminergic neurons in the embryonic mesencephalon of mice. Brain research Developmental brain research 86(1-2):101-113

52. Lie DC, Dziewczapolski G, Willhoite AR, Kaspar BK, Shults CW, Gage FH (2002) The adult substantia nigra contains progenitor cells with neurogenic potential. The Journal of neuroscience: the official journal of the Society for Neuroscience 22(15):6639-6649. doi:20026700

53. Shan X, Chi L, Bishop M, Luo C, Lien L, Zhang Z, Liu R (2006) Enhanced de novo neurogenesis and dopaminergic neurogenesis in the substantia nigra of 1-methyl-4-phenyl-1,2,3,6-tetrahydropyridine-induced Parkinson's disease-like mice. Stem Cells 24(5):1280-1287. doi:10.1634/stemcells.2005-0487

54. Zhao M, Momma S, Delfani K, Carlen M, Cassidy RM, Johansson CB, Brismar H, Shupliakov O, Frisen J, Janson AM (2003) Evidence for neurogenesis in the adult mammalian substantia nigra. Proc Natl Acad Sci USA 100(13):7925-7930. doi:10.1073/pnas.1131955100

55. Chocyk A, Przyborowska A, Dudys D, Majcher I, Mackowiak M, Wedzony K (2011) The impact of maternal separation on the number of tyrosine hydroxylase-expressing midbrain neurons during different stages of ontogenesis. Neuroscience 182:43-61. doi:10.1016/j.neuroscience.2011.03.008

56. Bjorklund A, Dunnett SB (2007) Dopamine neuron systems in the brain: an update. Trends in neurosciences 30(5):194-202. doi:10.1016/j.tins.2007.03.006

57. Sanges D, Comitato A, Tammaro R, Marigo V (2006) Apoptosis in retinal degeneration involves cross-talk between apoptosis-inducing factor (AIF) and caspase-12 and is blocked by calpain inhibitors. Proc Natl Acad Sci USA 103(46):17366-17371. doi:10.1073/pnas.0606276103

58. Pagida MA, Konstantinidou AE, Chrysanthou-Piterou MA, Patsouris ES, Panayotacopoulou MT (2020) Apoptotic Markers in the Midbrain of the Human Neonate After Perinatal Hypoxic/Ischemic Injury. J Neuropathol Exp Neurol 79(1):86-101. doi:10.1093/jnen/nlz114

59. Burke RE (1998) Programmed cell death and Parkinson's disease. Movement disorders: official journal of the Movement Disorder Society 13(Suppl 1):1723

60. Oo TF, Kholodilov N, Burke RE (2003) Regulation of natural cell death in dopaminergic neurons of the substantia nigra by striatal glial cell line-derived neurotrophic factor in vivo. The Journal of neuroscience: the official journal of the Society for Neuroscience 23(12):5141-5148. doi:10.1523/jneurosci.23$12-05141.2003$

61. Cheng S, Tereshchenko J, Zimmer V, Vachey G, Pythoud C, Rey M, Liefhebber J, Raina A, Streit F, Mazur A, Bähr M, Konstantinova P, Déglon N, Kügler S (2018) Therapeutic efficacy of regulable GDNF expression for Huntington's and Parkinson's disease by a high-induction, background-free "GeneSwitch" vector. Exp Neurol 309:79-90. doi:10.1016/j.expneurol.2018.07.017

62. Whone A, Luz M, Boca M, Woolley M, Mooney L, Dharia S, Broadfoot J, Cronin D, Schroers C, Barua NU, Longpre L, Barclay CL, Boiko C, Johnson GA, Fibiger HC, Harrison R, Lewis O, Pritchard G, Howell M, Irving C, Johnson D, Kinch S, Marshall C, Lawrence AD, Blinder S, Sossi V, Stoessl AJ, Skinner P, Mohr E, Gill SS (2019) Randomized trial of intermittent intraputamenal glial cell line-derived neurotrophic factor in Parkinson's disease. Brain 142(3):512525. doi:10.1093/brain/awz023

63. Tomac A, Widenfalk J, Lin LF, Kohno T, Ebendal T, Hoffer BJ, Olson L (1995) Retrograde axonal transport of glial cell line-derived neurotrophic factor in the adult nigrostriatal system suggests a trophic role in the adult. Proc Natl Acad Sci USA 92(18):8274-8278. doi:10.1073/pnas.92.18.8274

64. Blum M, Weickert CS (1995) GDNF mRNA expression in normal postnatal development, aging, and in Weaver mutant mice. Neurobiol Aging 16(6):925929. doi:10.1016/0197-4580(95)02011-x

65. Barroso-Chinea P, Cruz-Muros I, Aymerich MS, Rodríguez-Díaz M, Afonso-Oramas D, Lanciego JL, González-Hernández T (2005) Striatal expression of GDNF and differential vulnerability of midbrain dopaminergic cells. Eur J Neurosci 21(7):1815-1827. doi:10.1111/j.1460-9568.2005.04024.x

66. Saito H, Matsumoto M, Togashi H, Yoshioka M (1996) Functional interaction between serotonin and other neuronal systems: focus on in vivo microdialysis studies. Jpn J Pharmacol 70(3):203-205

67. Fujimiya M, Kimura H, Maeda T (1986) Postnatal development of serotonin nerve fibers in the somatosensory cortex of mice studied by immunohistochemistry. J Comp Neurol 246(2):191-201. doi:10.1002/cne.902460205

68. Fujimiya M, Hosoda S, Kitahama K, Kimura H, Maeda T (1986) Early development of serotonin neuron in the rat brain as studied by immunohistochemistry combined with tryptophan administration. Brain Dev 8(4):335-342

69. Wang X, Michaelis EK (2010) Selective neuronal vulnerability to oxidative stress in the brain. Front Aging Neurosci 2:12. doi:10.3389/fnagi.2010.00012 
70. Harris GJ, Codori AM, Lewis RF, Schmidt E, Bedi A, Brandt J (1999) Reduced basal ganglia blood flow and volume in pre-symptomatic, gene-tested persons at-risk for Huntington's disease. Brain 122(Pt 9):1667-1678

71. Rosas HD, Goodman J, Chen YI, Jenkins BG, Kennedy DN, Makris N, Patti M, Seidman LJ, Beal MF, Koroshetz WJ (2001) Striatal volume loss in HD as measured by MRI and the influence of CAG repeat. Neurology 57(6):1025-1028

72. Voelbel GT, Bates ME, Buckman JF, Pandina G, Hendren RL (2006) Caudate nucleus volume and cognitive performance: Are they related in childhood psychopathology? Biol Psychiatry 60(9):942-950. doi:10.1016/j.biopsych.2006.03.071

73. Kreczmanski P, Heinsen H, Mantua V, Woltersdorf F, Masson T, Ulfig N, Schmidt-Kastner R, Korr H, Steinbusch HW, Hof PR, Schmitz C (2007) Volume, neuron density and total neuron number in five subcortical regions in schizophrenia. Brain 130(Pt 3):678-692. doi:10.1093/brain/awl386

74. Reiss AL, Faruque F, Naidu S, Abrams M, Beaty T, Bryan RN, Moser H (1993) Neuroanatomy of Rett syndrome: a volumetric imaging study. Ann Neurol 34(2):227-234. doi:10.1002/ana.410340220

75. Perneczky R, Wagenpfeil S, Lunetta KL, Cupples LA, Green RC, Decarli C, Farrer LA, Kurz A (2010) Head circumference, atrophy, and cognition: implications for brain reserve in Alzheimer disease. Neurology 75(2):137-142. doi:10.1212/WNL.0b013e3181e7ca97

76. Kuan CY, Roth KA, Flavell RA, Rakic P (2000) Mechanisms of programmed cell death in the developing brain. Trends in neurosciences 23(7):291-297. doi:10.1016/s0166-2236(00)01581-2

77. Buss RR, Sun W, Oppenheim RW (2006) Adaptive roles of programmed cell death during nervous system development. Annu Rev Neurosci 29:1-35. doi:10.1146/annurev.neuro.29.051605.112800

78. Yamaguchi Y, Miura M (2015) Programmed cell death in neurodevelopment. Dev Cell 32(4):478-490. doi:10.1016/j.devcel.2015.01.019

79. Castagna C, Merighi A, Lossi L (2016) Cell death and neurodegeneration in the postnatal development of cerebellar vermis in normal and Reeler mice. Ann Anat 207:76-90. doi:10.1016/j.aanat.2016.01.010

\section{Figures}
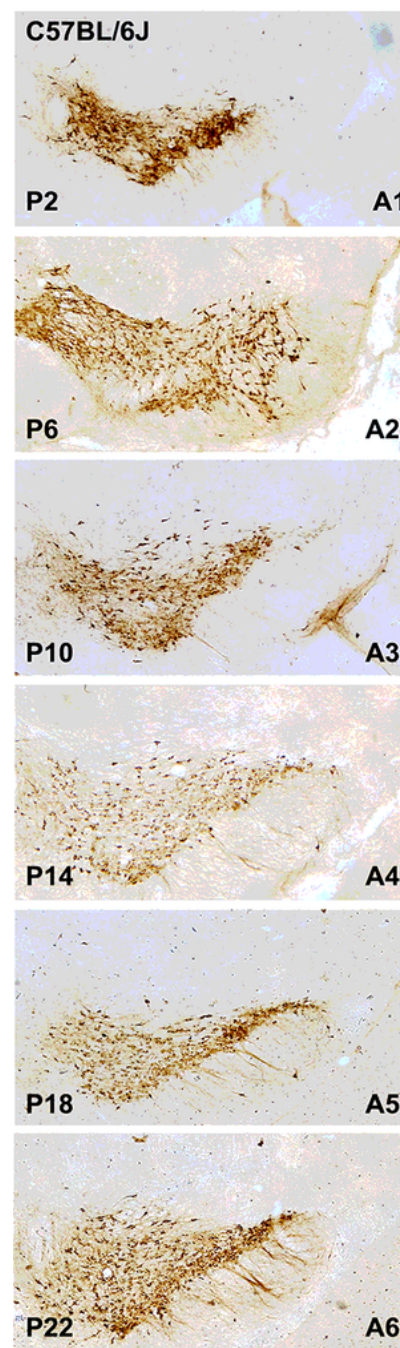

A5
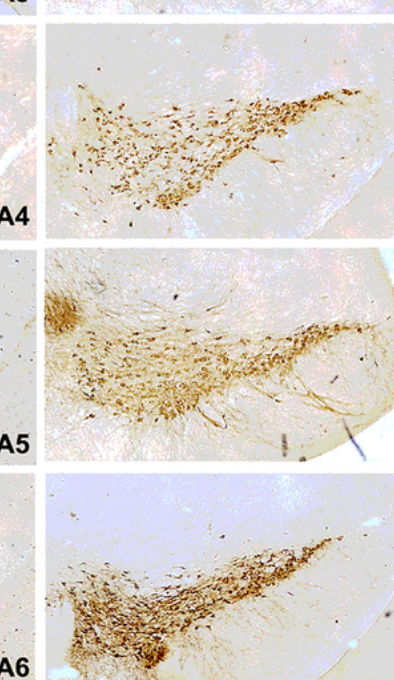

B3

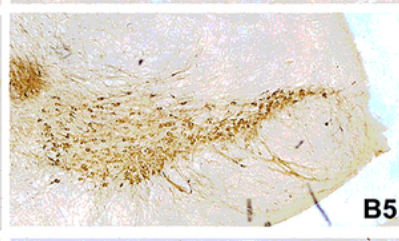

B4
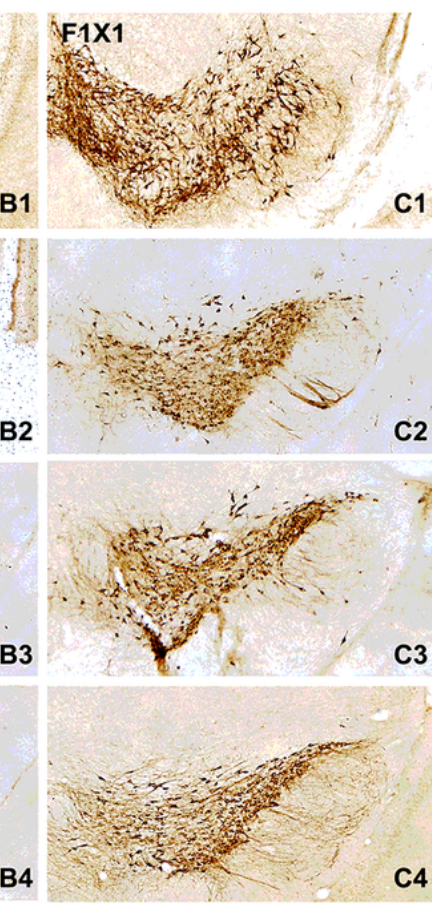

c1

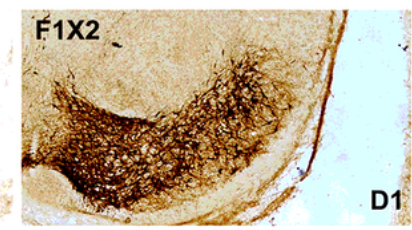

C2
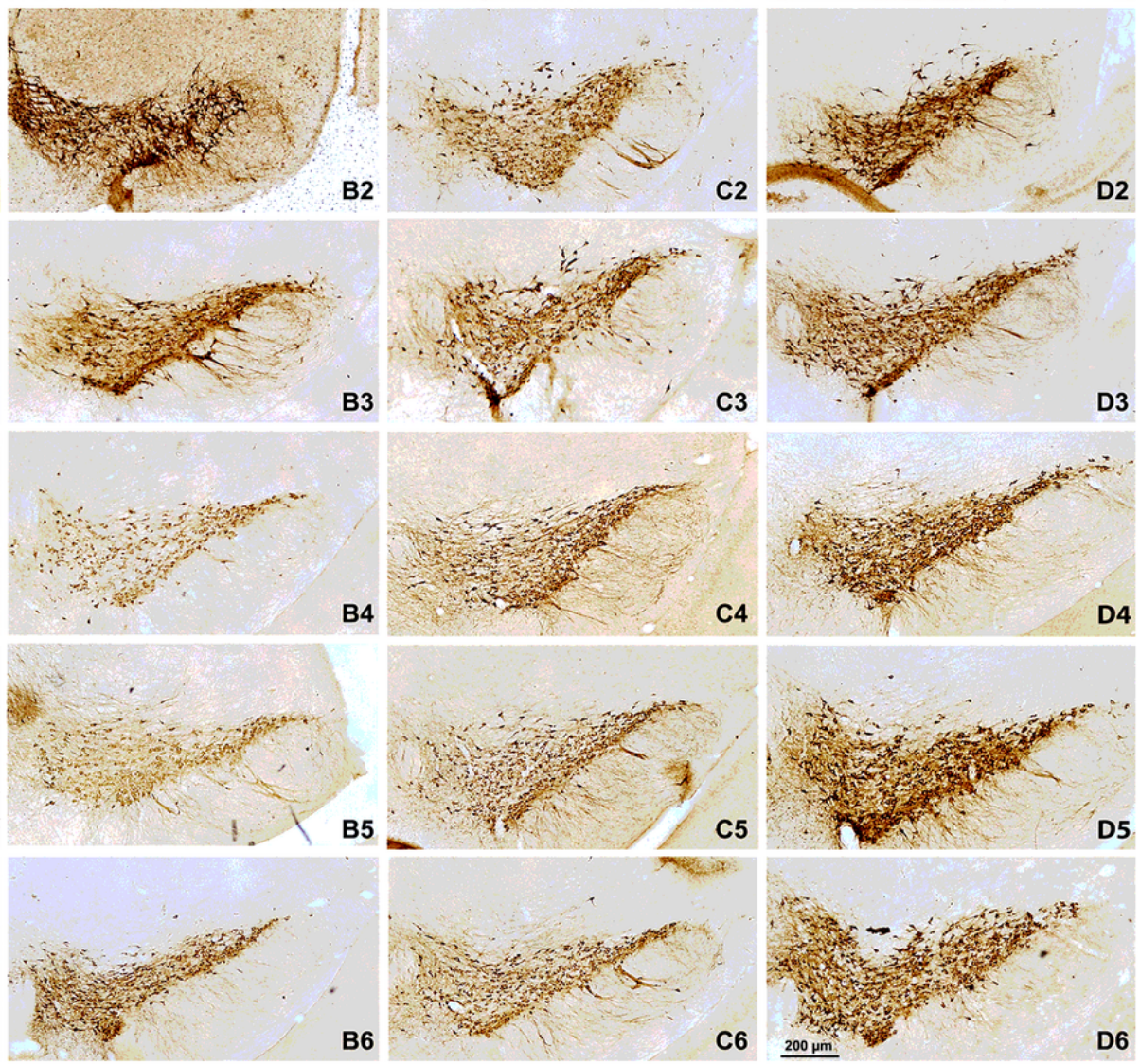

Figure 1 
Representative photomicrographs showing that nigral architecture matures earlier in MPTP resistant strains and they have more neurons:The SNpc and pars reticulata (SNpr) are largely indistinguishable at P2 (a1- d1). Note that, the dopaminergic neurons in the lateral nigra appeared at P6 in the other strains but at P10 in C57BL/6J (a3). By P10 the SNpc appear to be organized (a3-d3). Adult-like architecture of SNpc is evident at P14 in CD-1 (b4) and the crossbreds (c4d4), but at P18 in C57BL/6J (a4).
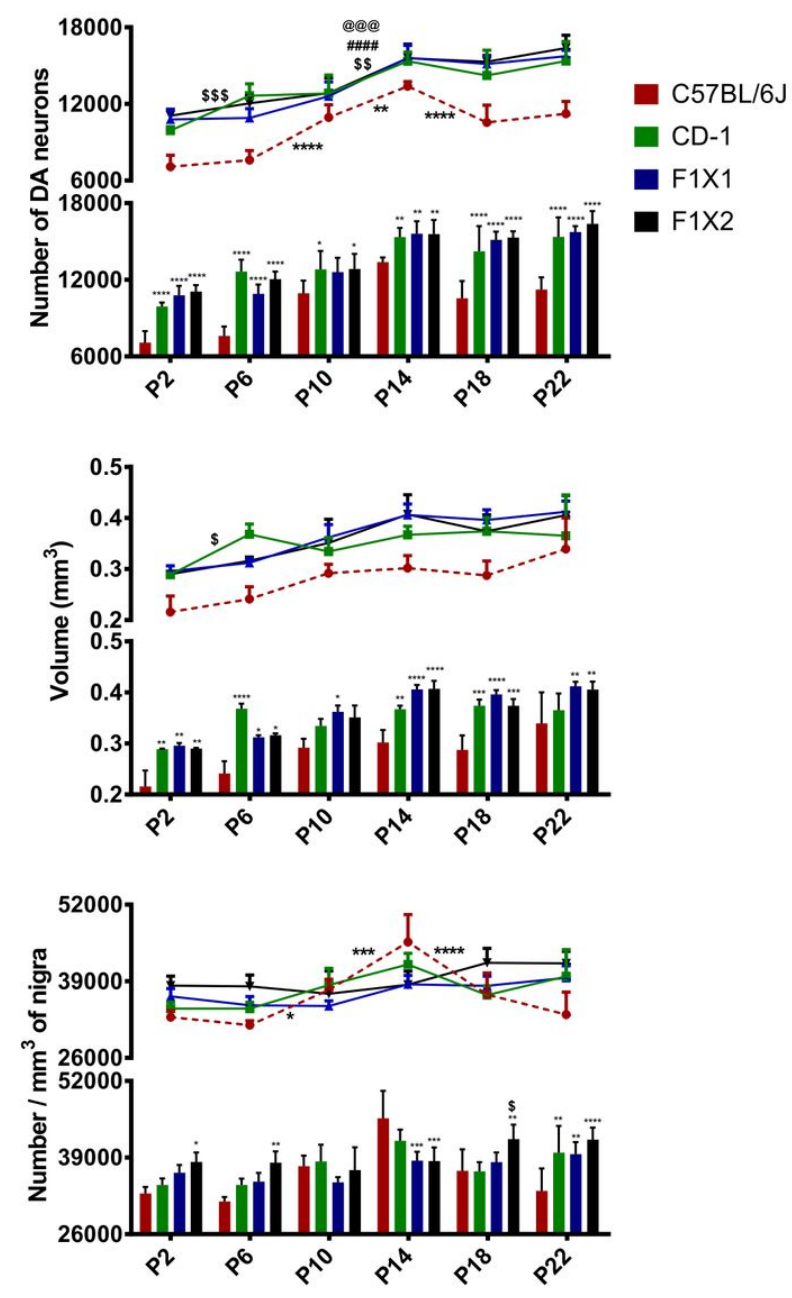

Figure 2

Histograms and line graphs showing alterations in nigral neuronal numbers (a) volume (b) and neuronal density (c). (a) The C57BL/6J mice had significantly fewer nigral neurons when compared to CD-1 and the crossbreds at P2 (P2, *** $p<0.0001$ C57BL/6J v/s CD-1, F1X1 \& F1X2). The numbers increased significantly thereafter in all the strains. The period of maximum increase was between P6 to P14. Note the reduction in numbers till P18, only in C57BL/6J (C57BL/6J, $* \star \star \star p<0.0001, P 14 \mathrm{v} / \mathrm{s} \mathrm{P} 18$ ) and stabilization at P22. (b)The nigral volume increased during development from P2 to adulthood across all the mice strains, with a peak at P14. Throughout development, C57BL/6J had much smaller nigra than CD-1 and crossbreds $\left({ }^{*} \mathrm{p}<0.05\right.$ to ${ }^{* * * *} \mathrm{p}<0.0001, \mathrm{C} 57 \mathrm{BL} / 6 \mathrm{~J} \mathrm{~V} / \mathrm{s}$ CD-1, F1X1 \& F1X2). (c)The dopaminergic neuronal density in the CD-1, F1X1 and F1X2 strains, remained comparable throughout development. Interestingly, the density also increased gradually to reach peak at P14 in C57BL/6J (C57BL/6J, * $p<0.05 \mathrm{P} 6 \mathrm{v} / \mathrm{s} \mathrm{P} 10$, *** $<<0.001 \mathrm{P} 10 \mathrm{v} / \mathrm{s} \mathrm{P} 14)$. A stability in number of neurons per unit area was acheived by $\mathrm{P} 22$ but was significantly lesser than CD-1 \& the crossbreds. 


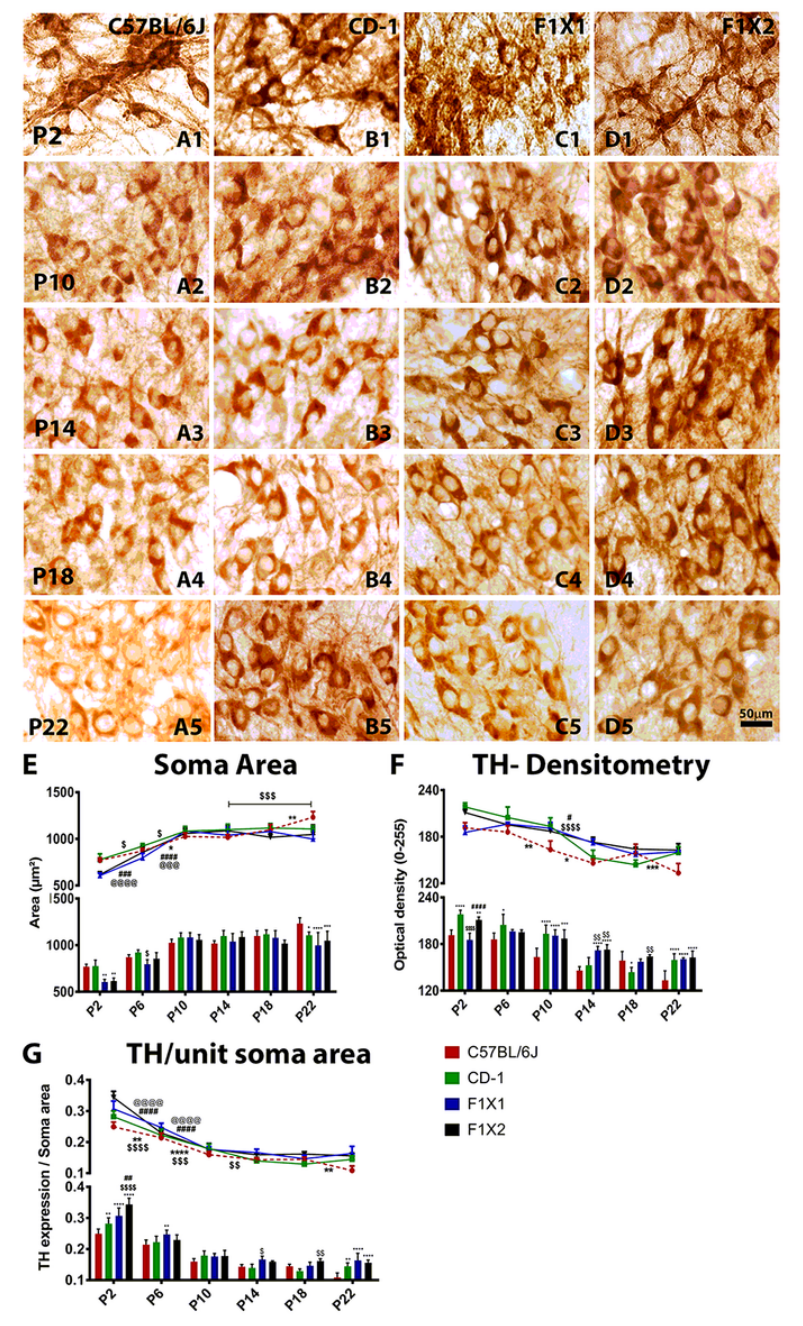

Figure 3

Representative photomigrographs of TH immunoractive SNpc neurons depicting the cellular morphology (a1-d5) and histograms (e-g) showing changes in size, cellular TH expression and TH/soma area during development: Cellular size and morphology (e): The dopaminergic neurons increased in size across strains (a1-d5) during development. At P2 the neurons of C57BL/6J and CD-1 were much larger than those of the crossbreds (a1 \& b1 v/s c1 \& d1

$\mathrm{p}<0.01, \mathrm{C} 57 \mathrm{BL} / 6 \mathrm{~J}$ \& CD-1 v/s F1X1 \& F1X2). The soma size was comparable across strains at P10, when they attained adult phenotype i.e. clear nuc Cellular TH expression (f): At P2 the TH expression in CD-1 and F1X2 was higher compared to C57BL/6J and F1X1. Stabilization of TH expression tc TH expression per unit soma area $(\mathrm{g})$ : TheF1X2 mice showed significantly more TH expression per unit soma area at P2 than C57BL/6J (P2,

$\$ \$ p<0.0001, C 57 B L / 6 J$ v/s F1X2). The reduction in the ratio stabilized at P14 in the CD-1, F1X1 and F1X2 midbrains, but at P22 in the C57BL/6J mice (C57BL/6J, **p<0.01, P18 v/s P22). 


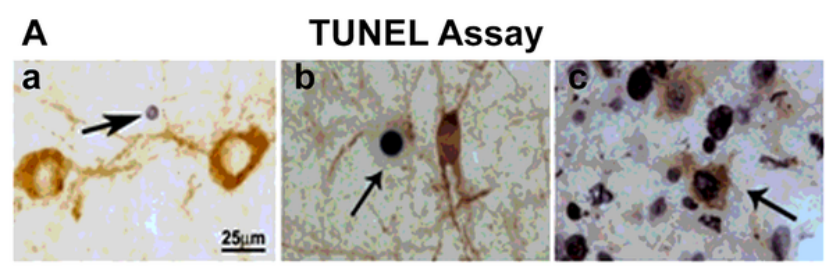

B
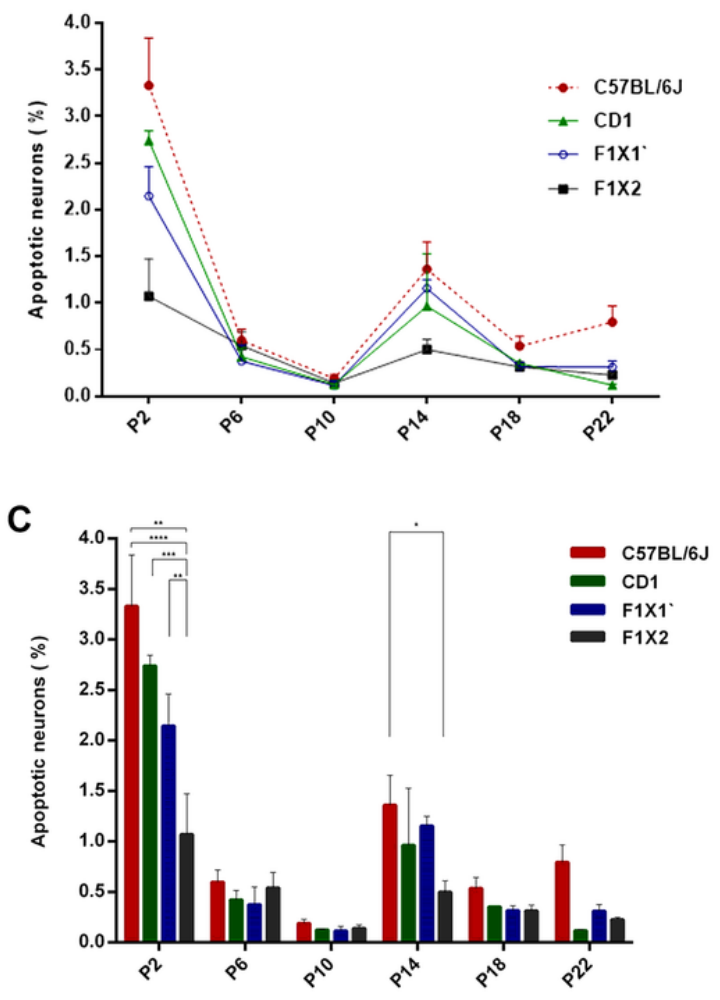

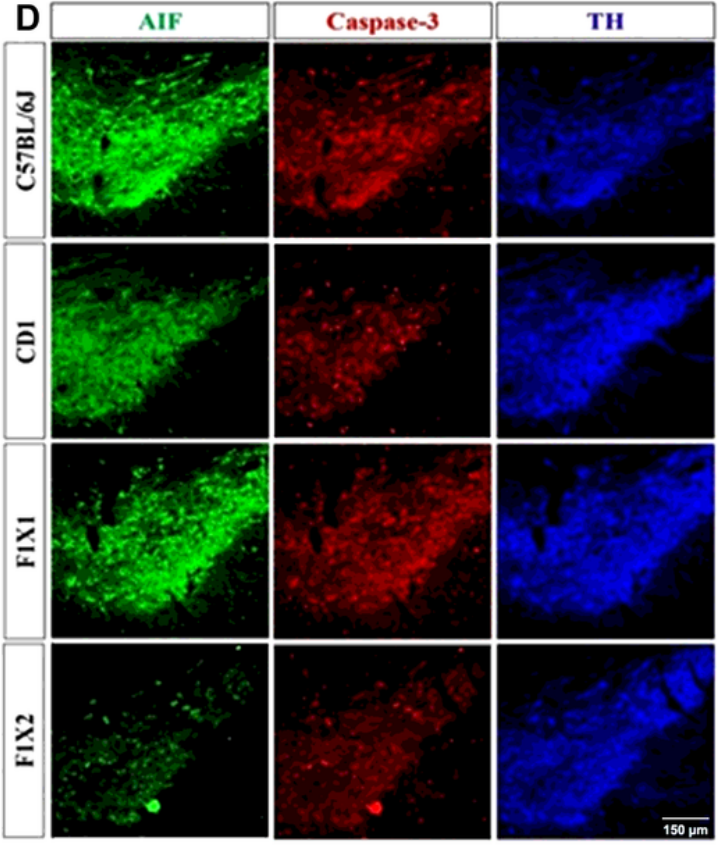

E

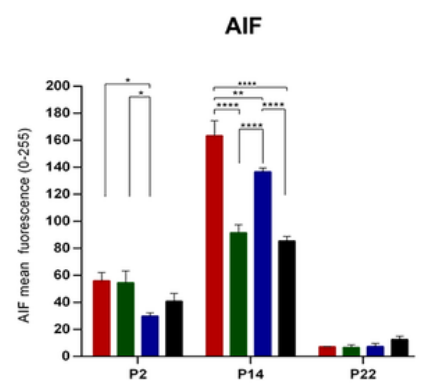

$\mathbf{F}$

Figure 4

Relatively pronounced developmental apoptosis in MPTP-susceptible C57BL/6J mice nigra. A. Representative photomicrographs showing TUNEL-positive apoptotic cells (black) present within TH-ir DA neurons in the substantia nigra of C57BL/6J mice at P14. (Aa) TUNEL-ir and TH-ve and (Ab) TUNEL-ir and TH co-labelled were seen n nigra. (Ac). Positive control. B. Scale: $25 \mu \mathrm{m}$. Graph showing two peaks in apoptosis, one at P2 and another at P14 across all the strains during development, indicated by \% apoptotic neurons. C. Histograms depicting \%TUNEL-ir cells. Note the significantly higher \% of TUNEL-ir cells in

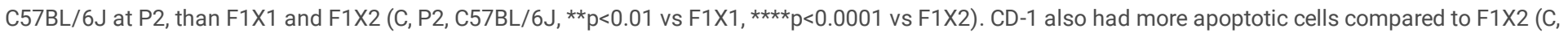
$P 2,{ }^{*} * \mathrm{p}<0.001, \mathrm{CD}-1$ vs F1X2). The difference in percent apoptotic neurons across mice strains was negligible at P6 and P10 (C, P6 and P10). At the second peak of P14, F1X2 had significantly fewer apoptotic neurons compared to C57BL/6J (C, P14, *p<0.05, C57BL/6J vs F1X2). D. Representative photomicrographs showing expression pattern of pro-apoptotic proteins AIF and caspase-3, co-labelled with TH in substantia nigra of C57BL/6J, CD-1, F1X1 and F1X2, at P14. (E \& F) Histograms depicting immunofluorescence intensity measurements. E. Note, at P2, DA neuronal (TH +ve) AIF expression was higher in both the parent strains, especially when compared to F1X1 (E, P2, * ${ }^{*}<0.05$; C57BL/6J vs F1X1 and CD-1 vs F1X1). At P14, C57BL/6J showed a significantly

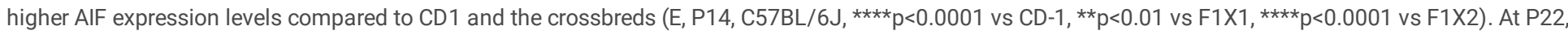
AIF expression was negligible across all the strains. F. Note, caspase-3 expression remained comparable across strains at P2. At P14, C57BL/6J showed a significantly higher caspase-3 expression compared to F1X2 (F, P14, ${ }^{*} \mathrm{p}<0.05, \mathrm{C} 57 \mathrm{BL} / 6 \mathrm{~J}$ vs F1X2, and a trend towards higher expression compared to CD-1. Note, caspase-3 expression in F1X1 was also significantly higher when compared to F1X2 (F, P14, **p<0.01, F1X1 vs F1X2). At P22, note a significantly higher caspase-3 expression in C57BL/6J when compared to CD1 and the crossbreds (F, P22, C57BL/6J, *p $<0.05$ vs CD-1, ${ }^{* \star *} \mathrm{p}<0.001$ vs F1X1, ${ }^{\star \star \star *} \mathrm{p}<0.0001$ vs F1X2). Interestingly, caspase-3 expression was significantly lower even in CD-1 when compared to F1X1. CD-1 and F1X2 compared well (P22, **p<0.01, CD-1 vs F1X1). All photomicrographs were captured at 10X magnification. 
A
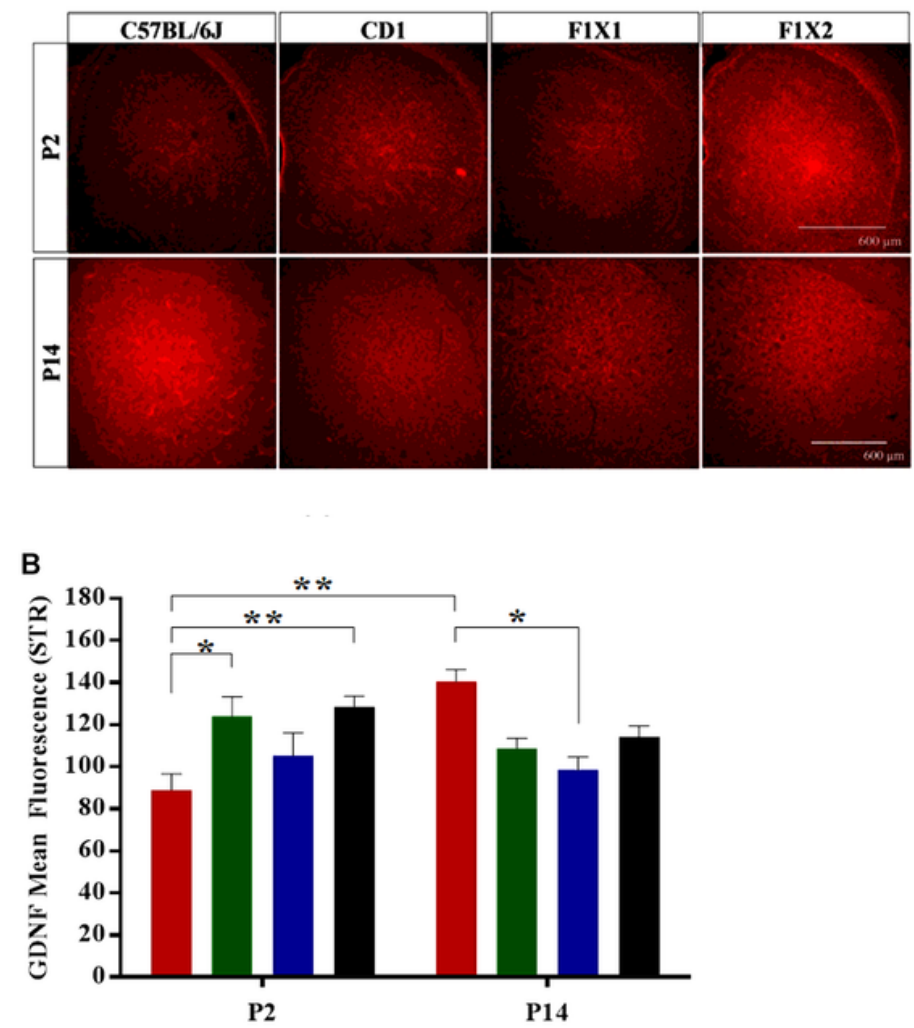
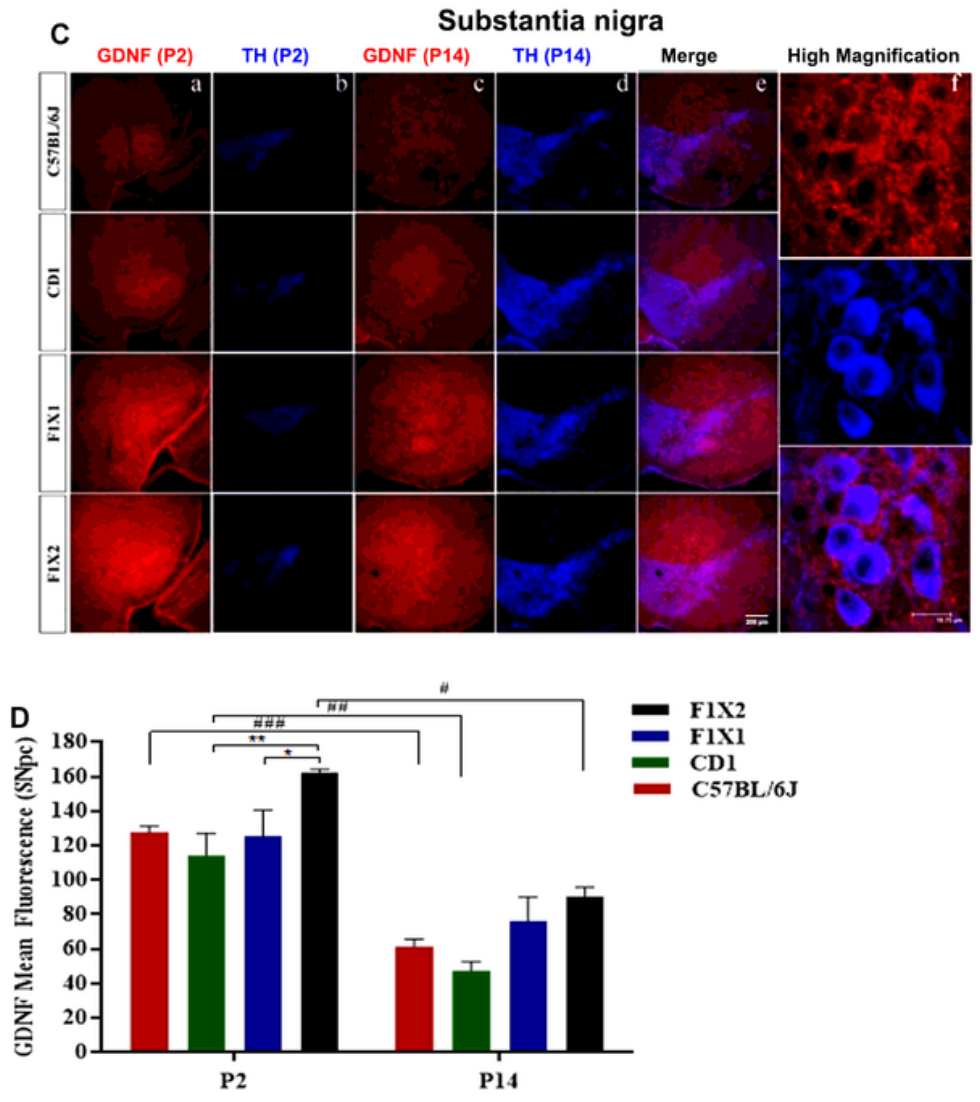

Figure 5

Nigrostriatal GDNF expression at time-points of peak apoptosis. A. Representative photomicrographs of striatal GDNF expression in C57BL/6J, CD-1, F1X1 and F1X2, at P2 and P14 time-points. B. Histograms depicting immunofluorescence intensity measurements. Note, striatum of C57BL/6J has significantly lower GDNF levels compared to CD-1 and F1X2 at P2 (B, P2, C57BL/6J, *p<0.05 vs CD-1, ** $<<0.01$ vs F1X2). In C57BL/6J compared to P2, it was more at P14 (B, C57BL/6J, **p<0.01, P2 vs P14). At P14 the GDNF expression was significantly higher in C57BL/6J than F1X1 (B, P14, *p<0.05, C57BL/6J vs F1X1). Scale: $600 \mu \mathrm{m}$. C. Representative photomicrographs of GDNF and TH co-labelled substantia nigra of C57BL/6J, CD-1, F1X1 and F1X2, at P2 and P14. Histogram (D). Note a significantly higher level of GDNF at P2, in F1X2 (D, P2, F1X2, ** $p<0.01$ vs CD-1, ${ }^{*} p<0.05$ vs F1X1). At P14, both F1X1 and F1X2 showed moderately higher nigral GDNF expression compared to parent strains (D, not significant). Note a significant down-regulation of nigral GDNF from $P 2$ to $P 14$ in all the strains, except F1X1 ( D, P14, C57BL/6J, \#\#\#p<0.001 P2 vs P14, CD-1, \#\#p<0.01 P2 vs P14, F1X2, \#p<0.05 P2 vs P14). Scale: enlarged: 18.75 um. All low magnification images were captured using $10 \mathrm{X}$ objective. 